\title{
Therapeutic actions of insulin-like growth factor I on APP/PS2 mice with severe brain amyloidosis
}

\author{
E. Carro ${ }^{\mathrm{a}, 1}$, J.L. Trejo $^{\mathrm{a}, 1}$, A. Gerber ${ }^{\mathrm{b}}$, H. Loetscher ${ }^{\mathrm{b}}$, J. Torrado $^{\mathrm{c}}$, \\ F. Metzger ${ }^{\mathrm{b}}$, I. Torres-Aleman ${ }^{\mathrm{a}, *}$ \\ ${ }^{a}$ Laboratory of Neuroendocrinology, Cajal Institute, CSIC, Avda. Dr. Arce 37, 28002 Madrid. Spain \\ ${ }^{\mathrm{b}}$ F. Hoffmann-LaRoche, CNS Preclinical Research, Basel, Switzerland \\ ${ }^{c}$ Department of Pharmaceutical Technology, School of Pharmacy, Complutense University, Madrid, Spain
}

Received 22 November 2004; received in revised form 22 June 2005; accepted 30 June 2005

Available online 23 September 2005

\begin{abstract}
Transgenic mice expressing mutant forms of both amyloid-beta (A $\beta$ ) precursor protein (APP) and presenilin (PS) 2 develop severe brain amyloidosis and cognitive deficits, two pathological hallmarks of Alzheimer's disease (AD). One-year-old APP/PS2 mice with high brain levels of $A \beta$ and abundant $A \beta$ plaques show disturbances in spatial learning and memory. Treatment of these deteriorated mice with a systemic slowrelease formulation of insulin-like growth factor I (IGF-I) significantly ameliorated AD-like disturbances. Thus, IGF-I enhanced cognitive performance, decreased brain $A \beta$ load, increased the levels of synaptic proteins, and reduced astrogliosis associated to $A \beta$ plaques. The beneficial effects of IGF-I were associated to a significant increase in brain A $\beta$ complexed to protein carriers such as albumin, apolipoprotein $\mathbf{J}$ or transthyretin. Since levels of APP were not modified after IGF-I therapy, and in vitro data showed that IGF-I increases the transport of $\mathrm{A} \beta /$ carrier protein complexes through the choroid plexus barrier, it seems that IGF-I favors elimination of $\mathrm{A} \beta$ from the brain, supporting a therapeutic use of this growth factor in AD.
\end{abstract}

(C) 2005 Published by Elsevier Inc.

Keywords: Alzheimer's disease; Insulin-like growth factor I; Therapy; Cognitive loss; Amyloidosis; Presenilin

\section{Introduction}

Alzheimer's disease (AD), the most common cause of dementia [18], is a disease of unknown etiology characterized by progressive memory loss, accumulation of extracellular deposits of amyloid $\beta$-peptide $(\mathrm{A} \beta)$, and tauopathy [11]. However, the relationship between brain pathology and clinical symptoms is not entirely clear yet $[5,16,20]$. For instance, transgenic mice overexpressing mutated APP showed poor correlation between $A \beta$ plaques and cognitive decline [15], while memory loss in $\mathrm{AD}$ models of amyloidosis can be rescued without reducing $A \beta$ load [7]. As a matter of fact cognitive deficits correlate better with

\footnotetext{
* Corresponding author. Tel.: +34 91585 4723; fax: +34 915854754.

E-mail address: torres@cajal.csic.es (I. Torres-Aleman).

1 Both authors contributed equally to this work.
}

lower synapse density than with accumulation of plaques [6].

Because there is a clear need for effective therapies in $\mathrm{AD}$, different animal models have been engineered to test new drugs. Most of these models age-dependently develop $\mathrm{A} \beta$ plaques and cognitive impairment $[12,14]$. Among these, the APP/PS2 mouse model overexpressing mutant forms of these human proteins develops progressive cognitive impairment together with early appearance of abundant $A \beta$ plaques [25], making it a useful system to test the efficacy of new therapies in reversal of AD-like disturbances. We have used APP/PS2 mice displaying AD-like impairments to investigate whether the cognitive and neuropathological disturbances associated with amyloidosis could be reversed by treatment with insulin-like growth factor I (IGF-I), a neurotrophic hormone that might be involved in the pathogenesis of $\mathrm{AD}$ through its ability to regulate brain $A \beta$ clearance [4]. As 
recently discussed [27], accumulation of $A \beta$ in $A D$ may be due to impaired degradation/clearance rather than increased production. Therefore, enhancement of $A \beta$ clearance through upregulation of $\mathrm{A} \beta$ carriers and transport through the bloodbrain-barriers [28] may be of therapeutic benefit in ADrelated amyloidosis.

\section{Material and methods}

\subsection{In vivo treatments}

One-year-old heterozygous APP/PS2 (congenic with C57BL/6J mice through repeated back-crosses; see [32]) and wild type C57BL/6J male mice were used. At this age, mutant animals already display $A \beta$ plaques and cognitive impairment [25]. Animals were kept under standard laboratory conditions following EEC guidelines. APP/PS2 mice were treated for 3 months with an IGF-I (GroPep, Australia) long-term release poly-lactide (Boehringer, Germany) microsphere formulation that results in stable and prolonged elevated blood IGF-I levels [1]. Subcutaneous (sc) injections of IGF-I microspheres (at a dose equivalent to $50 \mu \mathrm{g} / \mathrm{kg} /$ day) were given once every week as a suspension in sterile saline solution. Blank microspheres were given to the control group. At the end of the tenth week animals were tested in the watermaze and thereafter sacrificed. For evaluation of short-term effects of IGF-I on soluble brain A $\beta, 2-3$ or 6-10 months old APP/PS2 mice received four single IGF-I injections at the same $50 \mu \mathrm{g} / \mathrm{kg}$ dose i.p. over $24 \mathrm{~h}$ and brain $A \beta$ was analyzed thereafter. Additionally, the time course of $A \beta$ lowering by a single IGF-I application was analyzed with 2 months old APP/PS2 mice receiving a single $50 \mu \mathrm{g} / \mathrm{kg}$ IGFI i.p. dose; brain $A \beta$ was analyzed 2, 6 and $24 \mathrm{~h}$ thereafter, respectively.

\subsection{Behavioral evaluation}

Spatial memory was evaluated with a standard Morris water-maze test [21]. We followed procedures described previously [3] using intramaze and extramaze orientation cues [10]. After the animals were submitted to a 1 day habituation trial (day 1), in which preferences between tank quadrants in the different experimental groups were ruled out, for the subsequent 2-6 days the animals learned to find a hidden platform (acquisition). The next day (day 7), a probe trial without the platform was run to assess possible differences in swimming speed and preference for the platform quadrant. At days 16 and 17 animals were tested for long-term retention (memory) with the platform placed in the original location in the water tank. Evaluation of retention scores was made in 2 days to avoid the effect of a putative false extinction after 1 week of interval from the last day of acquisition (see Morris, 1984). In a single-day retention test animals may or not perform significantly worse than other groups, regardless of their scores in the acquisition test. Typically, this situation will either disappear in the second day, or on the contrary, will reveal a true lower ability to restore the learned memory (see for example, Frisch et al., 2000, and our previous work, Carro et al., 2001). On the last day of the test, a cued version protocol using a visible platform was conducted to determine sensorimotor and motivational status of the animals.

\subsection{Immunoassays}

Animals were perfused transcardially with saline buffer or $4 \%$ paraformaldehyde in $0.1 \mathrm{M}$ phosphate buffer (PB, $\mathrm{pH}$ 7.4) for biochemical and immunohistochemical analysis, respectively. Western-blot (WB) and immunoprecipitation were performed as described [24]. For WB of APP and Cterminal fragment (C99), brains were extracted in Tris/EDTA containing $8 \mathrm{M}$ urea and protease inhibitors and immunostained with the WO-2 antibody that recognizes APP and C99. Streptavidin-peroxidase and ECL was used for detection. Brain levels of $A \beta$ and $A \beta$ plaque-load were determined by ELISA and immuno-morphometry, respectively, as described [4]. To reveal A $\beta$ plaques, coronal brain sections were serially cut and pre-incubated in $88 \%$ formic acid. Plaque burden is expressed as percentage of brain area covered with amyloid. An anti-A $\beta$ (MBL, Nagoya, Japan) that recognizes rodent and human $\mathrm{N}$-terminal $A \beta$ forms was used for immunoprecipitations and detection of $A \beta$ deposits. For detection of human $A \beta$, we used a human specific antibody to $A \beta(6 \mathrm{E} 10$, Sigma, Missouri) in the lower layer and anti-A $\beta_{1-40}$ or anti$A \beta_{1-42}$-specific antibodies (Calbiochem, California) in the top layer. To quantify both soluble and insoluble forms of $A \beta$, samples were extracted with formic acid and centrifuged at high speed, and supernatants were assayed as described [30]. Antibodies used include anti-albumin (Bethyl, Texas), antitransthyretin (Santa Cruz, California), anti-apolipoprotein J (Chemicon, California), anti-synaptophysin (Sigma), antidynamin 1 (Santa Cruz), and anti-GFAP (Sigma). All were used at 1:500-1:2000 dilution. Secondary antibodies were Alexa-coupled (Molecular Probes, Oregon).

To measure gliosis associated to $A \beta$ plaques, double fluorescence immunohistochemistry was conducted at the same time with all the antibodies, animal groups, and sections. All pictures were taken by the same experimenter using a Leica DMRB microscope with a $40 \times$ objective, doubleblind labeled, with a Nikon Coolpix 955 applying a fixed digital zoom. Selected areas were analyzed with AIS software to obtain the area of positive surfaces. Data are presented as the ratio of $\mathrm{GFAP}^{+}$area to $\mathrm{A}^{+}$area. Both areas must be inside the reference space. In turn, the reference space was a virtual circle centered in the midpoint of the plaque. The virtual circle radius was twice the radius of the amyloid plaque as determined in its sharp focus. This procedure assured that (1) the measured fluorescence is truly associated to plaques and is proportional to the size of each plaque; and that (2) whatever the size of each plaque, the data represent the gliosis per plaque area unit, so the 
data were not depending on the relative plaque sizes, as plaques vary widely in size while reactive astrocytes appear similar.

\subsection{In vitro blood-brain barrier assay}

A double-chamber choroid plexus epithelial cell culture system mimicking the blood-cerebrospinal (CSF) interface [29], was used as described in detail before [4]. Epithelial cells were seeded on transwell-clear filter inserts (Costar Plastics, Massachussets) precoated on the upper side with laminin (Becton Dickinson, Massachussets). In permeability studies, blood-to-CSF flux was referred as basolateral-toapical transfer, whereas, CSF-to-blood flux was referred as apical-to-basolateral transfer. For apical-to-basolateral analysis, 24-wells plate inserts covered by a confluent monolayer of epithelial cells were placed into each well and $0.5 \mathrm{ml}$ of DMEM containing the compound or compounds of interest was added to the upper compartment. Upper- and lowerchamber medium was collected and analyzed by WB. For basolateral-to-apical transport studies, after addition of the different proteins in the lower chamber the medium was collected from the upper chamber and processed as described. Laminin-coated filters without cells were used in duplicate as controls. Medium with $A \beta_{1-40}(5 \mu \mathrm{g} / \mathrm{ml}$, Calbiochem $)$, albumin $(1 \mu \mathrm{g} / \mathrm{ml}$, Sigma), or transthyretin $(1 \mu \mathrm{g} / \mathrm{ml}$, Calbiochem) was added to either the apical (upper) or basolateral (lower) chamber for different periods of time. All measurements were done in triplicate.

\subsection{Statistics}

A $t$-test was performed when comparing two groups, and a one-way ANOVA was used for comparing multiple groups. For behavioral analysis, a multiple measures ANOVA followed by a post hoc Tukey test was applied.

\section{Results}

\subsection{IGF-I therapy reverses AD-like disturbances in APP/PS2 mice}

As seen in previous studies using a cued-water maze test [25], 1-year-old APP/PS2 mice show cognitive deficits also in the standard version of the water maze (Fig. 1). These deficits were reversed by chronic treatment with systemic IGF-I (Fig. $1 ;{ }^{*} p<0.005$ and ${ }^{* *} p<0.05$ versus control and IGF-I treated). Thus, learning (acquisition) and memory (retention) scores in the water-maze were not different in IGF-I treated APP/PS2 mice from those found in wild type congenic C57BL/6J mice. Locomotor (swimming speed) and sensorimotor skills, as well as motivational state were indistinguishable between both groups of APP/PS2 mice and control C57BL/6J mice, as determined with the probe and visible platforms tests (not shown). Therefore, treatment during 3 months with IGF-I reverses spatial learning and memory deficits in this mouse model of Alzheimer's amyloidosis.

We next determined whether behavioral recovery after IGF-I therapy was paralleled by changes in brain $A \beta$ levels. Quantification of $A \beta_{1-40}$ and $A \beta_{1-42}$ by ELISA shows that both were significantly reduced by IGF-I (Fig. 2A; $p<0.05$ and $p<0.01$, respectively). Furthermore, amyloid burden (determined by brain surface area covered by $A \beta$ plaques) was also significantly reduced after IGF-I therapy (Fig. 2B, $p<0.01$ versus vehicle-treated APP/PS2 mice). In addition, the extent of gliosis determined by total brain GFAP levels was modified after IGF-I (Fig. 2C) and the amount of reactive astroglia associated with $\mathrm{A} \beta$ plaques appeared significantly reduced (Fig. $2 \mathrm{C}, p<0.01$ versus non-treated APP/PS2 mice). Reactive astrocytes surrounded every $\mathrm{A} \beta$ plaque and distal cellular processes penetrated into the plaque (Fig. 2C). The decrease after IGF-I treatment consisted mainly in the amount of $\mathrm{GFAP}^{+}$cellular processes infiltrating the plaques related

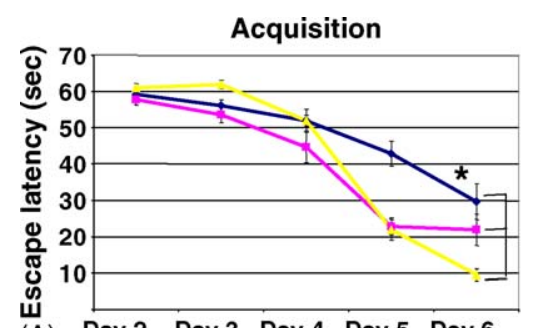

(A) Day 2 Day 3 Day 4 Day 5 Day 6
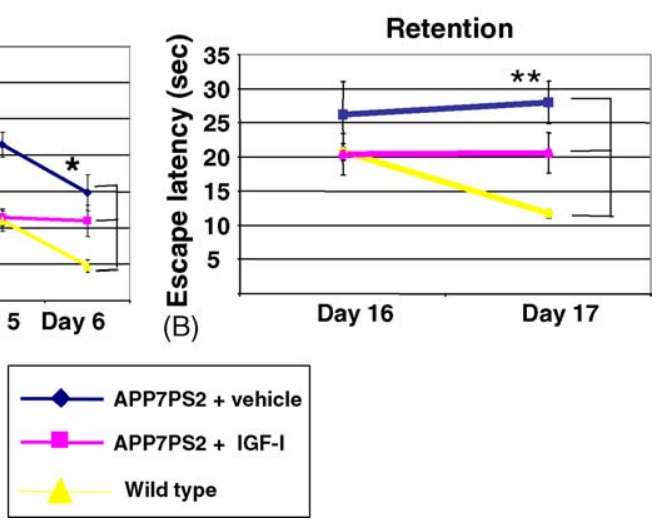

Fig. 1. Cognitive impairment in APP/PS2 mice is ameliorated by IGF-I therapy. (A) In the water maze test APP/PS2 mice show significantly impaired performance in learning the location of the hidden platform. Treatment with IGF-I corrected this deficit: after IGF-I mutant mice performed similarly to control wild type ( $F=11.28 ;{ }^{*} p<0.005$ vs. wild type and APP/PS2 mice treated with IGF-I). (B) In addition, only vehicle-treated mutant mice show long-term retention (memory) deficits. Non-treated APP/PS2 mice performed significantly worse that IGF-I-treated mice in the time to find the platform in the second day of the retention test. IGF-I treated animals performed similarly to controls $\left(F=6.38 ;{ }^{* *} p<0.05\right.$ vs. IGF-I treated and control wild type; $n=12-15$ per group). 

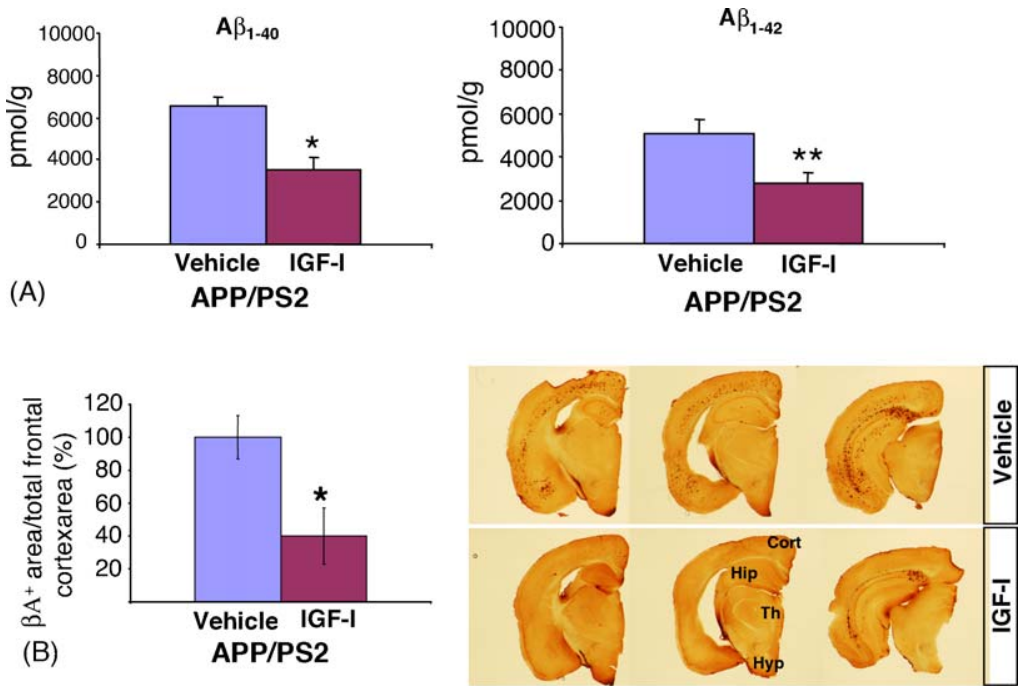

(C)
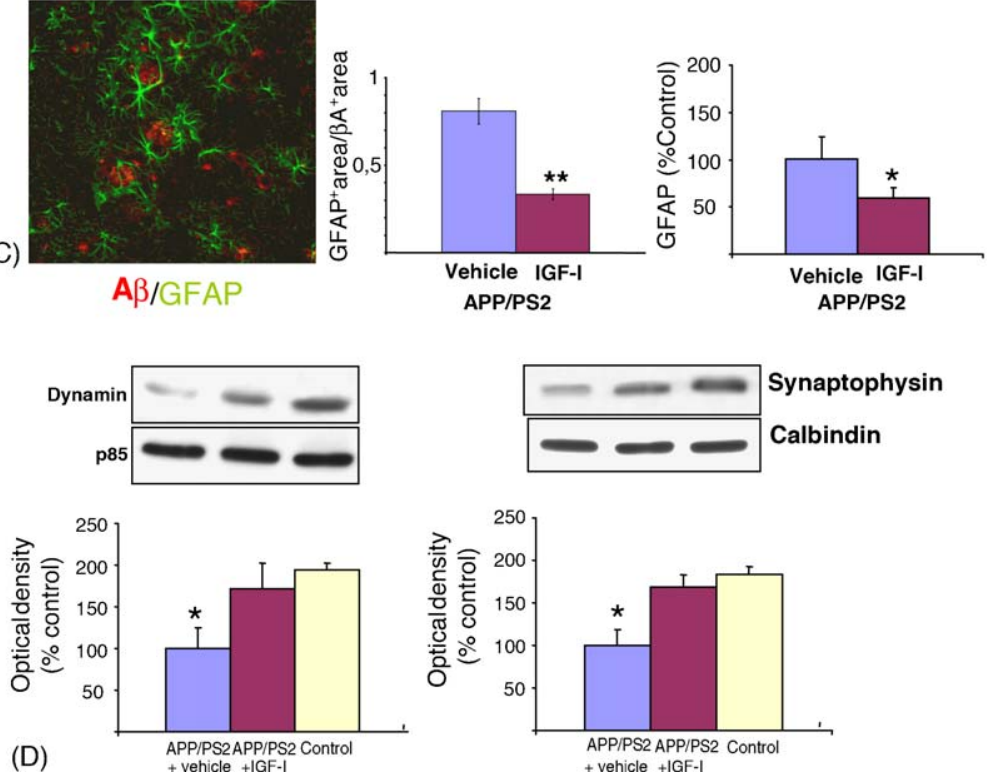

Fig. 2. IGF-I therapy reduces AD-like biochemical disturbances in APP/PS2 mice. (A) Total levels of brain A $\beta_{1-40}$ and A $\beta_{1-42}$ in APP/PS2 mice were extracted in $70 \%$ formic acid and measured by ELISA. Both significantly decreased after IGF-I treatment. ${ }^{*} p<0.05,{ }^{* *} p<0.01$ vs. non-treated APP/PS2 mice ( $\left.n=5-6\right)$. (B) Amyloid deposits in cortex of APP/PS2 mice are significantly decreased by IGF-I treatment ( $p<0.05$ vs. vehicle-treated APP/PS2). Murine (endogenous) and human (transgenic) $\mathrm{A} \beta$ were detected with an antibody that recognizes both human and murine $\mathrm{A} \beta$. Quantification histograms and representative consecutive brain sections of IGF-I and vehicle-treated APP/PS2 mice are shown. Note the marked decrease in immunoreactive A $\beta$ deposits found in the IGF-I treated mouse. Cor: cerebral cortex, Hip: hippocampus, Th: thalamus, Hyp: hypothalamus. $(n=12-15)$. (C) IGF-I treatment reduced astrogliosis (stained with GFAP in green) in brain cortex associated with $\mathrm{A} \beta$ plaques (identified with anti-A $\beta$, in red). ${ }^{* *} p<0.01$ vs. vehicle-treated APP/PS2 mice ( $\left.n=7\right)$. (D) Synaptic proteins dynamin- 1 and synaptophysin are significantly increased by IGF-I treatment in APP/PS2 mice. Representative WBs and corresponding densitometric measurements are shown. Lower blot shows equal protein load as determined by an unrelated protein (p85PI3K). Values were corrected to total protein load. ${ }^{*} p<0.05$ vs. non-treated mutant mice $(n=12-15)$.

to the size of the plaque, rather than the number of astrocytes per plaque.

Cognitive decline in $\mathrm{AD}$ is most likely related to synaptic impairment [17]. In human patients, several proteins associated to the synapse such as the synaptic vesicle proteins dynamin 1 and synaptophysin are reduced [17,34]. Notably, APP/PS2 mice showed reduced levels of both, that were nor- malized by IGF-I (Fig. 2D; $p<0.05$ versus treated APP/PS2 and control mice).

\subsection{IGF-I favors elimination of $A \beta$ from the brain}

IGF-I regulates brain $A \beta$ clearance through enhanced $\mathrm{A} \beta$ carrier-mediated transport [4]. Therefore, we measured 

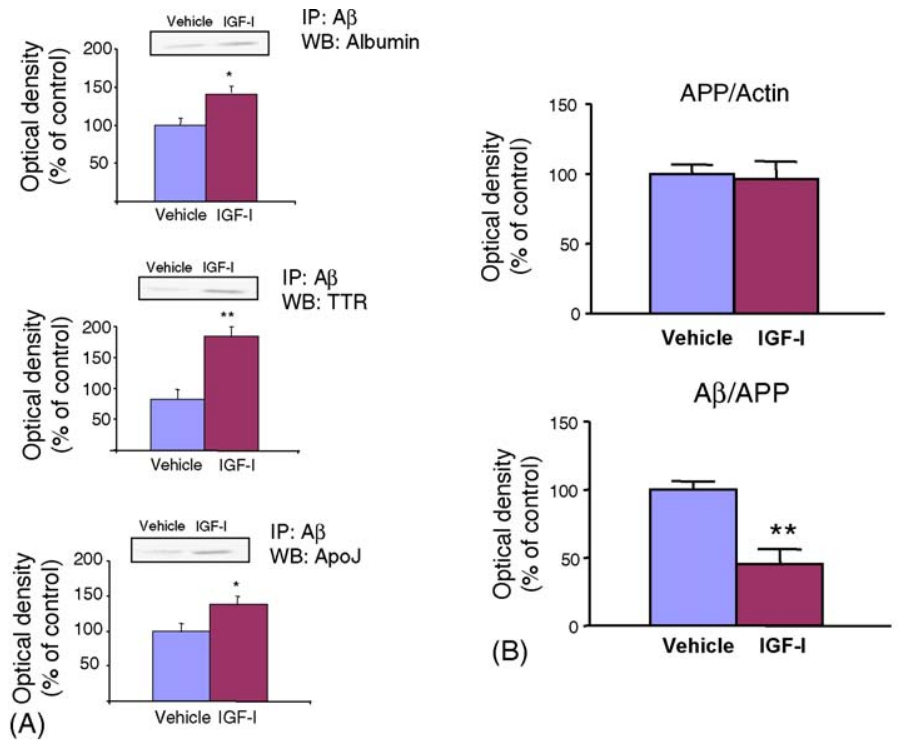

(B)

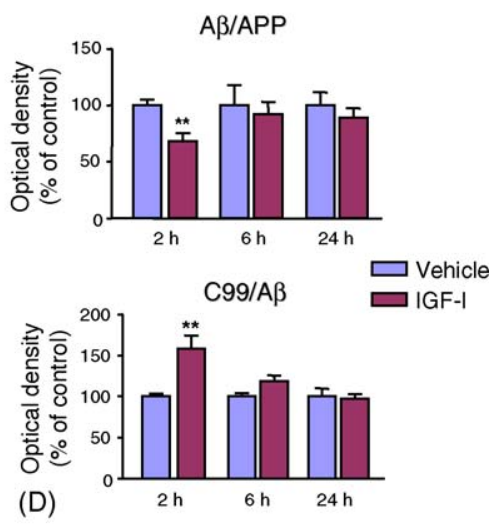

Fig. 3. IGF-I modulates clearance of $A \beta$ in vivo. (A) WB of the $A \beta$ carriers albumin, transthyretin (TTR) and apolipoprotein $J(A p o J)$ in $A \beta$ immunoprecipitates of brain cortex obtained from APP/PS2 mice. Protracted IGF-I treatment modified levels of the three A $\beta /$ carrier complexes. ${ }^{* *} p<0.001$ and ${ }^{*} p<0.05$ vs. vehicletreated APP/PS2 mice $(n=12-15)$. (B) The production of APP is not changed after 3 months of IGF-I therapy in 1-year-old APP/PS2 mice. WB of APP and A $\beta$ show unchanged APP/Actin ratio while, as expected, the A $\beta / A P P$ ratio was significantly decreased after IGF-I ${ }^{* *} p<0.01, n=5-6$ per group). (C) Repeated administration of IGF-I for only $24 \mathrm{~h}$ is sufficient to produce a decrease in brain A $\beta$ levels without affecting production of APP or its degradation (measured by C99/APP levels). While total levels of APP and the ratio C99/APP are not changed, the ratio A $\beta / A P P$ is decreased while the ratio C99/A $\beta$ is increased. ${ }^{* *} p<0.01$ vs. vehicle-treated APP/PS2 mice ( $n=12 ; 1$-year-old mice). (D) Time course analysis after a single injection of IGF-I (50 $\left.\mu \mathrm{g} / \mathrm{kg}\right)$ shows a rapid action of IGF-I in promoting elimination of brain $A \beta$ as indicated by the corresponding changes in the A $\beta / A P P$ and C99/A $\beta$ ratios $2 \mathrm{~h}$ after the injection of IGF-I that return to baseline levels $6 \mathrm{~h}$ after the injection. ${ }^{* *} p<0.01$ vs. vehicle-treated mice $(n=10-13 ; 2$-month-old animals).

the amount of brain $A \beta$ complexed with $A \beta$ carriers such as albumin, transthyretin and apolipoprotein $\mathrm{J}$ after IGF-I therapy. We observed that the $A \beta$ complexes were significantly increased in IGF-I treated APP/PS2 mice (Fig. 3A). In turn, while IGF-I administration lowered $A \beta$ levels (Figs. 2A and 3B), it did not affect the production of APP. After IGF-I therapy for 3 months, the normalized levels of human APP were not changed in the brains of APP/PS2 mice (Fig. 3B). Further analysis of the clearance actions of IGF-I on brain $A \beta$ levels showed that administration of IGF-I to APP/PS2 mice for only $24 \mathrm{~h}$ is sufficient to lower brain A $\beta$ without affecting APP production or degradation (the latter was measured by levels of $\mathrm{C} 99$, the $\beta$-secretase product of APP degradation, see Fig. 3C). Similar results were obtained in younger animals (not shown). The $\mathrm{A} \beta$ lowering effects of IGF-I are very rapid and transient, as determined through time-course analysis after a single injection of IGF-I which showed that only $2 \mathrm{~h}$ after IGF-I injection the $A \beta$ lowering effect is visible whereas at 6 and $24 \mathrm{~h}$ it had disappeared (Fig. 3D).

We next analyzed whether IGF-I induces transport of $A \beta$ across blood brain barrier cells using a double-chamber culture system that mimics the CSF-blood barrier [29]. These experiments indicated that $\mathrm{A} \beta$ efflux is enhanced by IGFI, favoring CSF-to-blood transport (Fig. $4 \mathrm{~A}, p<0.01$ versus control dishes). Efflux of $A \beta$ from the "CSF side" into the "blood side" of the well was markedly increased after exposure of the epithelial cells to IGF-I while the opposite route 

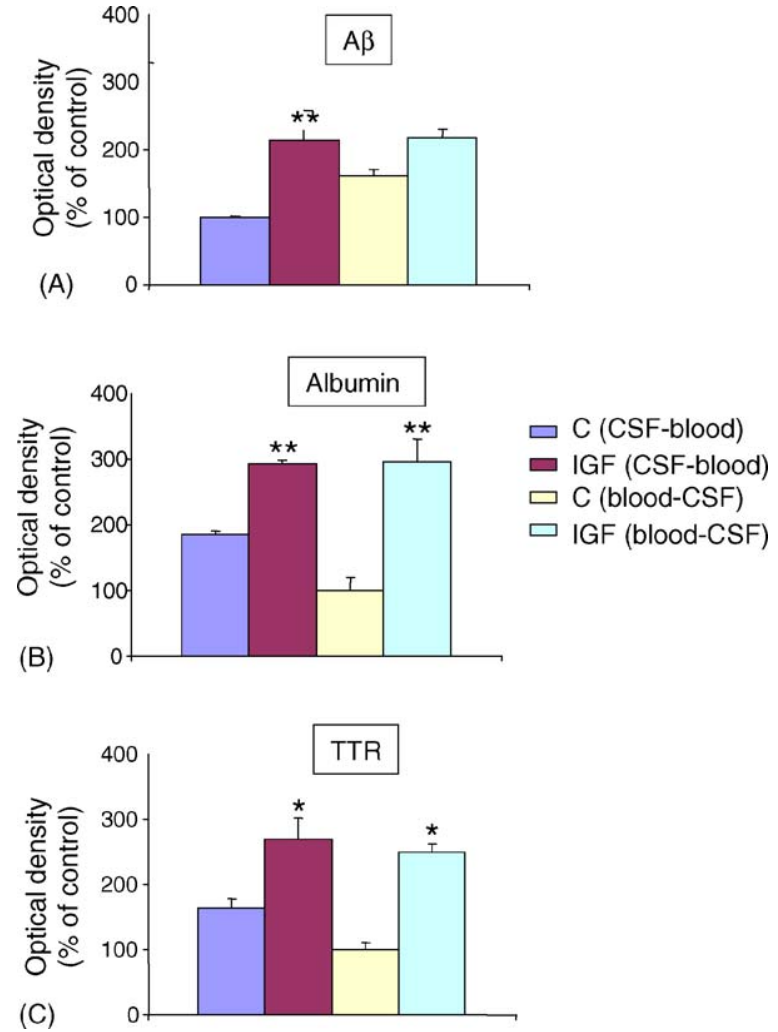

Fig. 4. IGF-I favors clearance of $A \beta$ in vitro. (A) In vitro transport of $A \beta$ through a choroid plexus epithelial monolayer is modulated by IGFI. Addition of $A \beta$ to the upper chamber (CSF side) and IGF-I in the lower chamber (blood side) induces enhanced accumulation of $A \beta$ in the lower chamber (blood side). However, blood-to-CSF transit of $A \beta$ was not significantly affected by the presence of IGF-I. ${ }^{* *} p<0.01$ vs. control dishes (C, in the absence of IGF-I, $n=4$ ). (B) In vitro transport of albumin and (C) transthyretin (TTR) through the epithelial monolayer is markedly increased by IGF-I in both directions, from the upper (CSF side) to the lower chamber (blood side), and vice-versa. ${ }^{*} p<0.05,{ }^{* *} p<0.01$.

was modestly enhanced in the presence of IGF-I. In contrast, albumin and transthyretin transport across the epithelial monolayer shows a more symmetrical behavior in response to IGF-I. When either protein is added in the presence of IGFI, transport is favored, regardless of the direction analyzed (Fig. 4B and C).

\section{Discussion}

The present results indicate that systemic IGF-I therapy for 3 months reverses the impairment of spatial learning and memory in APP/PS2 mice and reduces total brain A $\beta$ load. IGF-I treatment ameliorates also other AD-related disturbances such as low synaptic protein levels in cerebral cortex and plaque-associated gliosis. Based on these observations, and that IGF-I has recently been approved for several rare human diseases, we consider that IGF-I therapy for $\mathrm{AD}$ patients can be rapidly implemented.

The most important therapeutic goal in $\mathrm{AD}$ is to ameliorate cognitive disturbances, the clinically relevant deficit in these patients, and the reason they are usually first diagnosed. Therefore, the ability of IGF-I to restore cognitive function to normal levels in deteriorated animals is of therapeutic significance. In previous studies, APP/PS2 mice were shown to develop both learning and memory impairments in the water-maze test [25]. These observations were obtained in mutant mice with a hybrid background (C57BL/6J $\times$ DBA/2) using a cued-version of the Morris test that includes memory and learning tasks in the acquisition phase of the test. In the present study we used congenic animals in the C57BL/6J background and instead used the standard version of the water maze to separate memory from learning tasks. Therefore, regardless of their genetic background and water-maze paradigm used, APP/PS2 mice have impaired hippocampal-dependent cognition, a typical deficit seen in AD patients. Most significatly, this was corrected by IGF-I therapy.

We previously showed that IGF-I reduces brain A $\beta$ plaque formation in the Tg2576 mouse model of amyloidosis when treatment was initiated prior to development of plaques [4]. In the present study we used APP/PS2 mice that have more abundant plaques that appear earlier as compared to $\mathrm{Tg} 2576$ mice. This is because mutant presenilins accelerate plaque formation and favor the production of amyloidogenic forms [13]. Since we started treatment at 1 year of age, when APP/PS2 mice already bear abundant plaques [25], we may conclude that IGF-I therapy not only inhibits $A \beta$ accumulation, but also eliminates already formed deposits. Thus, treatment with systemic IGF-I appears to reduce brain amyloidosis in advanced stages of the process, reinforcing the notion that it might be useful in AD patients at later stages of the disease.

While there is not yet firm evidence of the mechanism leading to brain $\mathrm{A} \beta$ accumulation in $\mathrm{AD}$, decreased clearance of $A \beta$ from brain and CSF to the general circulation has been suggested as its main cause [35]. However, this process is still poorly studied. Since the production of $A \beta$, as determined by measuring levels of its precursor APP, was not modified by treatment with IGF-I, while total A $\beta$ load was decreased, it appears that IGF-I, as recently shown by us [4] is favoring clearance of brain $A \beta$. This conclusion is further supported by (1) the presence of higher levels of $A \beta$ complexed to its carrier proteins after IGF-I therapy, (2) the acute decreasing action of IGF-I on brain A $\beta$ levels, (3) the absence of increased APP degradation after acute administration of IGF-I, and (4) the ability of IGF-I to promote outward efflux of $A \beta$ through a choroid plexus epithelial monolayer that mimics the CSF-toblood barrier.

All types of CNS injuries result in reactive gliosis $[19,26]$. Indeed, astrocytosis is another hallmark of plaque-associated pathology in AD. Well before the age of onset of IGF-I treatment, at 9 months of age, APP/PS2 mice show the first signs of an inflammatory process, mainly reactive astrogliosis correlating with $\mathrm{A} \beta$ deposits [25]. While astrogliosis associated with $A \beta$ plaques was markedly reduced after chronic IGFI treatment, total gliosis appeared less affected. Again, the 
stage at which IGF-I treatment starts may be crucial to reverse pathological alterations since in $\mathrm{Tg} 2576$ mice IGF-I abrogated also widespread gliosis when treated at earlier stages of the process [4].

Brains of $\mathrm{AD}$ patients have reduced synaptic contacts and lower levels of proteins associated to synapses [17,22,34]. As already mentioned, lower synapse density correlates with cognitive deficits [6]. The finding that IGF-I increased levels of dynamin 1 and synaptophysin, two proteins with important functions in synaptic vesicle trafficking [23], suggests an additional neuroprotective mechanism of IGF-I. For example, in the absence of normal levels of dynamin 1 , synaptic terminals will become incapable of supplying adequate synaptic vesicles resulting in altered synaptic transmission [33] and memory loss [8]. Thus, enhancement of proteins involved in synaptic function likely contributes to cognitive recovery after IGF-I.

In summary, our findings confirm previous suggestions of a potential therapeutic benefit of systemic IGF-I therapy in neurodegenerative diseases [3,9,31], and, more specifically in AD-related amyloidosis [2].

\section{Acknowledgements}

The authors are grateful to J. Sancho for his expert help. We further thank R. Wybrecht and P. Biry for excellent technical support and greatly acknowledge D. Antequera for animal husbandry. This work was supported by a grant from CAM (08.5/0063.1/2003).

\section{References}

[1] Carrascosa C, Torres-Aleman I, Lopez-Lopez C, Carro E, Espejo L, Torrado S, et al. Microspheres containing insulin-like growth factor I for treatment of chronic neurodegeneration. Biomaterials 2004;25(4):707-14.

[2] Carro ET-AI. Insulin-like growth factor I and Alzheimer's disease: therapeutic prospects? Exp Rev Neurother 2004;4(1):7986.

[3] Carro E, Trejo JL, Busiguina S, Torres-Aleman I. Circulating insulinlike growth factor I mediates the protective effects of physical exercise against brain insults of different etiology and anatomy. $J$ Neurosci 2001;21(15):5678-84.

[4] Carro E, Trejo JL, Gomez-Isla T, LeRoith D, Torres-Aleman I. Serum insulin-like growth factor I regulates brain amyloid-beta levels. Nat Med 2002;8(12):1390-7.

[5] Davis JN, Chisholm JC. The 'amyloid cascade hypothesis' of AD: decoy or real McCoy? Trends Neurosci 1997;20(12):558-9.

[6] DeKosky ST, Scheff SW. Synapse loss in frontal cortex biopsies in Alzheimer's disease: correlation with cognitive severity. Ann Neurol 1990;27(5):457-64.

[7] Dodart JC, Bales KR, Gannon KS, Greene SJ, DeMattos RB, Mathis $\mathrm{C}$, et al. Immunization reverses memory deficits without reducing brain Abeta burden in Alzheimer's disease model. Nat Neurosci 2002;5(5):452-7.

[8] Dubnau J, Grady L, Kitamoto T, Tully T. Disruption of neurotransmission in Drosophila mushroom body blocks retrieval but not acquisition of memory. Nature 2001;411(6836):476-80.
[9] Fernandez AM, de la Vega AG, Torres-Aleman I. Insulin-like growth factor I restores motor coordination in a rat model of cerebellar ataxia. Proc Natl Acad Sci USA 1998;95(3):1253-8.

[10] Frisch C, Dere E, Silva MA, Godecke A, Schrader J, Huston JP. Superior water maze performance and increase in fear-related behavior in the endothelial nitric oxide synthase-deficient mouse together with monoamine changes in cerebellum and ventral striatum. J Neurosci 2000;20(17):6694-700.

[11] Hardy J, Selkoe DJ. The amyloid hypothesis of Alzheimer's disease: progress and problems on the road to therapeutics. Science 2002;297(5580):353-6.

[12] Hsiao K, Chapman P, Nilsen S, Eckman C, Harigaya Y, Younkin $\mathrm{S}$, et al. Correlative memory deficits, Abeta elevation, and amyloid plaques in transgenic mice. Science 1996;274(5284):99-102.

[13] Jankowsky JL, Fadale DJ, Anderson J, Xu GM, Gonzales V, Jenkins NA, et al. Mutant presenilins specifically elevate the levels of the 42 residue beta-amyloid peptide in vivo: evidence for augmentation of a 42-specific gamma secretase. Hum Mol Genet 2004;13(2):159-70.

[14] Janus C, Phinney AL, Chishti MA, Westaway D. New developments in animal models of Alzheimer's disease. Curr Neurol Neurosci Rep 2001;1(5):451-7.

[15] Kumar-Singh S, Dewachter I, Moechars D, Lubke U, De Jonghe $\mathrm{C}$, Ceuterick $\mathrm{C}$, et al. Behavioral disturbances without amyloid deposits in mice overexpressing human amyloid precursor protein with Flemish (A692G) or Dutch (E693Q) mutation. Neurobiol Dis 2000;7(1):9-22.

[16] Lue LF, Kuo YM, Roher AE, Brachova L, Shen Y, Sue L, et al. Soluble amyloid beta peptide concentration as a predictor of synaptic change in Alzheimer's disease. Am J Pathol 1999;155(3):853-62.

[17] Masliah E, Mallory M, Alford M, DeTeresa R, Hansen LA, McKeel Jr DW, et al. Altered expression of synaptic proteins occurs early during progression of Alzheimer's disease. Neurology 2001;56(1):127-9.

[18] Mayeux R. Epidemiology of neurodegeneration. Annu Rev Neurosci 2003;26:81-104

[19] McGraw J, Hiebert GW, Steeves JD. Modulating astrogliosis after neurotrauma. J Neurosci Res 2001;63(2):109-15.

[20] McLean CA, Cherny RA, Fraser FW, Fuller SJ, Smith MJ, Beyreuther K, et al. Soluble pool of Abeta amyloid as a determinant of severity of neurodegeneration in Alzheimer's disease. Ann Neurol 1999;46(6):860-6.

[21] Morris R. Developments of a water-maze procedure for studying spatial learning in the rat. J Neurosci Meth 1984;11(1):47-60.

[22] Mufson EJ, Counts SE, Ginsberg SD. Gene expression profiles of cholinergic nucleus basalis neurons in Alzheimer's disease. Neurochem Res 2002;27(10):1035-48.

[23] Okamoto PM, Gamby C, Wells D, Fallon J, Vallee RB. Dynamin isoform-specific interaction with the shank/ProSAP scaffolding proteins of the postsynaptic density and actin cytoskeleton. J Biol Chem 2001;276(51):48458-65.

[24] Pons S, Torres-Aleman I. Insulin-like growth factor-I stimulates dephosphorylation of Ikappa B through the serine phosphatase calcineurin (protein phosphatase 2B). J Biol Chem 2000;275(49):38620-5.

[25] Richards JG, Higgins GA, Ouagazzal AM, Ozmen L, Kew JN, Bohrmann B, et al. PS2APP transgenic mice, coexpressing hPS2mut and hAPPswe, show age-related cognitive deficits associated with discrete brain amyloid deposition and inflammation. J Neurosci 2003;23(26):8989-9003.

[26] Rostworowski M, Balasingam V, Chabot S, Owens T, Yong VW. Astrogliosis in the neonatal and adult murine brain post-trauma: elevation of inflammatory cytokines and the lack of requirement for endogenous interferon-gamma. J Neurosci 1997;17(10):3664-74.

[27] Selkoe DJ. Clearing the Brain's Amyloid Cobwebs. Neuron 2001;32(2):177-80

[28] Shibata M, Yamada S, Kumar SR, Calero M, Bading J, Frangione B, et al. Clearance of Alzheimer's amyloid-ss(1-40) peptide from 
brain by LDL receptor-related protein-1 at the blood-brain barrier. J Clin Invest 2000;106(12):1489-99.

[29] Strazielle N, Ghersi-Egea JF. Demonstration of a coupled metabolism-efflux process at the choroid plexus as a mechanism of brain protection toward xenobiotics. J Neurosci 1999;19(15):6275-89.

[30] Suzuki N, Cheung TT, Cai XD, Odaka A, Otvos Jr L, Eckman C, et al. An increased percentage of long amyloid beta protein secreted by familial amyloid beta protein precursor (beta APP717) mutants. Science 1994;264(5163):1336-40.

[31] Trejo JL, Carro E, Garcia-Galloway E, Torres-Aleman I. Role of insulin-like growth factor I signaling in neurodegenerative diseases. J Mol Med 2004;82(3):156-62.
[32] von Kienlin M, Kunnecke B, Metzger F, Steiner G, Richards JG, Ozmen L, et al. Altered metabolic profile in the frontal cortex of PS2APP transgenic mice, monitored throughout their life span. Neurobiol Dis 2005;18(1):32-9.

[33] Yao PJ. Synaptic frailty and clathrin-mediated synaptic vesicle trafficking in Alzheimer's disease. Trends Neurosci 2004;27(1):24-9.

[34] Yao PJ, Zhu M, Pyun EI, Brooks AI, Therianos S, Meyers VE, et al. Defects in expression of genes related to synaptic vesicle trafficking in frontal cortex of Alzheimer's disease. Neurobiol Dis 2003;12(2):97-109.

[35] Zlokovic BV. Cerebrovascular transport of Alzheimer's amyloid beta and apolipoproteins $\mathrm{J}$ and $\mathrm{E}$ : possible anti-amyloidogenic role of the blood-brain barrier. Life Sci 1996;59(18):1483-97. 